\title{
Acylglycine Measurement
}

National Cancer Institute

\section{Source}

National Cancer Institute. Acylglycine Measurement. NCI Thesaurus. Code C156534.

The determination of the amount of acylglycine present in a sample. 